\title{
Coffee Anyone? An Unstructured Capital Budgeting Project To Encourage Critical Thinking Skills In Accounting Students
}

Katherine J. Silvester, Ph.D., Siena College, USA

\begin{abstract}
This paper presents an unstructured, semester-long team-based capital budgeting project for senior level undergraduate accounting students. Successfully completing this project requires accounting students to step outside of their narrow accounting transactions framework and to apply extensive organizational, analytical, information gathering, and critical thinking skills. Specifically, this project requires students to assess a market opportunity, define the scope of their analysis, and to structure their own business solution to the problem. Students are then required to collect external data with which to project annual after-tax net income, after-tax cash flows, and the associated performance measures. Based on their financial analysis, students must subsequently assess the viability of their solution and reach a "go" or "no-go" decision.
\end{abstract}

Keywords: Capital Budgeting; Market Opportunity; Unstructured Analysis; Critical Thinking; Student Project; Business Plan

"What matters is that we determine how to add high value to our students as they prepare for careers in a fastchanging business world. We have the capability to do that, but we need to step outside our comfort zone, stretch ourselves, and begin to teach and research in new areas." (Albrecht and Sack, 2000, 59)

\section{INTRODUCTION}

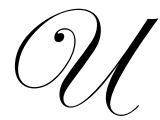

ndergraduate accounting education has undergone extreme scrutiny over the past few decades. Study groups have recommended changes to both the content and the underlying analytical approach within accounting curricula (AECC, 1990). More liberal arts, writing, research, and ethics courses have been added to the typical accounting curriculum. Changes in the Educational Requirement for CPA licensure have driven the normalization of the 150 hour accounting education. Therefore, both content and structural changes have occurred throughout accounting education programs.

However, the internal structure of most accounting courses remains firmly entrenched in lectures, case analyses, textbook homework assignments, and literature-based research papers. In general, these day-to-day pedagogical activities are relatively circumscribed and structured. Accounting students rarely need to "go outside" of the classroom, printed literature, or a written case description in order to be successful.

This paper presents a market-based research and analysis project for undergraduate senior accounting majors. This project forces them to step out of their passive comfort zone of textbooks and case material, and to actively enter, analyze, and solve real market problems.

\section{PROJECT DESCRIPTION}

\section{Project Overview}

Student teams are provided with a written description of a potential market opportunity at the beginning of 
the semester. This unstructured Business Opportunity Statement presents conflicting data and information regarding a potential market opportunity. The Business Opportunity Statement for a recent semester's project is included as Appendix A. This particular Business Opportunity Statement describes the problems encountered by students and faculty that do not have access to adequate food and beverage services in their main academic building. ${ }^{1}{ }^{2}$

Student teams are required to de-construct the market opportunity and to design their own business solution. Students generally greatly enjoy this phase of the project and enthusiastically embark upon brainstorming exercises to generate potential solutions.

Along with the Business Opportunity Statement, students are also given the Team Project Description (Appendix B). The Team Project Description lays out the detailed requirements, deliverables, due dates, and evaluation criteria for the project. The required secondary and primary research will enable the student teams to prepare revenue and cost projections that support their development of a business strategy and plan. Their work culminates in the preparation of a capital budgeting proposal that includes an After-Tax Cash Flow Statement, an Income Statement, a reconciliation of the two statements, and calculation of the relevant performance measures (net present value, internal rate of return, and payback period). ${ }^{3}$ Successfully completing the project requires the student teams to conduct extensive market-based research and to employ sophisticated technical analyses, and - more importantly - to employ a significant level of critical thinking skills.

An end-of-semester student poster presentation session requires each student team to make a recommendation regarding the feasibility of the business that they have proposed and analyzed. Invited attendees at the poster presentation session have an opportunity to interact with and provide valuable input and feedback to the student teams. At the instructor's option, attendees can be asked to vote for "Best Visual Display" and the "Best New Business Proposal." When the presentation session is over, students provide feedback on their team experience by completing a "Confidential Peer Evaluation" (Appendix E).

This project has been used successfully for over 8 years with teams of accounting majors. ${ }^{4}$ The project usually presents advanced ${ }^{5}$ undergraduate students with their first opportunity to thoroughly analyze a business problem that they, themselves, have structured. As such, this experience can result in significant growth in the business acumen and the critical thinking skills of the students involved.

\section{Common Challenges}

The unstructured nature of this project requires both the instructor and the student teams to stretch themselves in myriad ways. Some of the common challenges and potential ameliorating strategies are listed below.

\footnotetext{
${ }^{1}$ The Business Opportunity Statement in Appendix A has been generalized to increase its usability. However, with minor changes, the Statement could be personalized to make the project more relevant and engaging for the student project teams at a specific college. For example, most colleges can probably identify an academic, residence hall, or library building that does not have adequate beverage and snack services.

${ }^{2}$ Different Business Opportunity Statements can be developed, as desired. It is essential that students can easily relate to the Business Opportunity, so the teams can concentrate on the business and market analysis, without being overwhelmed by industrial complexity or technology issues. Previous Business Opportunities have included a fast food business that was attempting to adopt "greener" business practices (without sacrificing profits) and a popular off-campus eatery/pub that was experiencing dangerously overwhelming crowds, but had no room for physical expansion.

${ }^{3}$ Examples of a typical project After-Tax Cash Flow Statement, Income Statement, and the reconciliation between the two are included in Appendices C and D.

${ }^{4}$ This undergraduate student project was inspired by a more complex and extended two-semester project developed previously for graduate management and technology students enrolled in an MBA program. The current project is more circumscribed in terms of market and technology analysis, but significantly more involved in terms of accounting applications and financial analysis (Silvester, et al., 2002).

${ }^{5}$ The project is currently included in an upper level elective accounting course for seniors (Advanced Cost Accounting).
} 


\section{Stretching the Students}

Getting Started. The tendency of students to procrastinate is increased by the size and complexity of this project. Therefore, it is helpful to introduce the project to the students at the earliest possible time. The instructor can distribute the Business Opportunity Statement (Appendix A) and the Team Project Description (Appendix B) to students on the first day of class. The student teams can then be formed during the second day of class, and the teams can be required to meet briefly during the class period and to settle upon their first outside-of-class meeting time and location.

Difficulty of the Technical Material. Senior level accounting majors should have already covered Basic Cash Flow and Present Value Analysis. However, the introduction of tax effects, combined with accounting gains and losses, is a significant increase in the difficulty level of the analysis. Adding the requirement of reconciling the after-tax cash flows and after-tax net income will stretch students even further technically. In order to prepare the teams for the technical challenges inherent in the project, it is recommended that the instructor cover Capital Budgeting, AfterTax Cash Flow Analysis, and Performance Measurement as early as possible in the semester. ${ }^{6}$

Data Overload and Lack of Availability. Typically, students will begin to collect information from the internet regarding potential costs and revenues. Within a short time, students will be overwhelmed by the level of detail that the project seems to require. Unless their natural accounting tendency to enmesh themselves hopelessly in the details is managed, the students will not be able to complete the project. Therefore, the instructor will need to regularly assure the students that reasonable "guesstimates" of small items are perfectly acceptable. The students need to be encouraged to spend their limited amount of time on the large value items, rather than spinning their wheels on the pennies. Additionally, the instructor can assure the students that identifying a potential cost or revenue item on the Cash Flow Spreadsheet is more important than getting an exact dollar estimate for that item. ${ }^{7}$

There will also be instances where students simply can't reasonably estimate costs. Again, the instructor needs to assure the students that identifying the cost item is much more important than having a perfect estimate. At the same time, students can frequently acquire more information than they think they can. For example, a student may be able to obtain construction "guesstimates" from a friend's brother, who is a contractor.

Reality of Imperfect Decision Making. Students must struggle with and resolve the dilemma that while their cost and revenue estimates are flawed, they must use these flawed estimates to make decisions. Students need to structure their time so that they can collect reasonable amounts of data, create the resulting financial statements, calculate the performance measures and then have time to reflect upon their work and begin another iteration of estimation, calculation, and reflection. Students will routinely struggle with the need for incorporating this iterative process into their project schedule. ${ }^{8}$ Some students may try to resolve the flawed data dilemma by chasing the fantasy of perfect estimates. As a result, they may not have time to reflect upon and analyze their own work within the allotted time frame. Some students may try to escape the dilemma by spending too little time on data research and collection. These students will need to be reminded that their grade is dependent upon the quality and quantity of their research.

Hesitancy to Interact with the Market. Students frequently show reluctance to visit businesses and interview real managers and business leaders. However, encouragement and a requirement to take and display pictures is usually enough of an incentive to overcome their initial reluctance.

"Do Not Fund" Recommendations. When students reach the end of their analysis, it is very common for them to discover than their project is not financially viable. This causes intense anxiety, and students will ask for guidance and reassurance. The instructor can raise a number of points for the teams to consider, rather than automatically accepting the situation.

\footnotetext{
${ }^{6}$ Chapter 21 of Horngren, et al., 2012, provides an excellent coverage of the technical material.

${ }^{7}$ Periodically checking the progress of the teams with short meetings (in or outside of class) will prove invaluable in keeping the teams on track.

${ }^{8}$ Accounting students, in particular, seem to be comfortable with the typical structured and non-iterative textbook problem. As a result, the accounting student can be particularly resistant to iterative and unstructured problem solving.
} 
- $\quad$ Are there any changes than you can make to increase the viability of your project? Can you do anything significantly differently?

- $\quad$ Are your revenues projected too conservatively or your costs too aggressively?

- $\quad$ How did you project revenues? What have your marketing classes taught you? ${ }^{9}$

- What critical assumptions have you made?

- What assumption(s) would have to change in order for your project to be viable?

Finally, students may need to be reminded that objectively identifying a nonviable project is both acceptable and valuable.

\section{Stretching the Instructor}

Guiding the Student Teams. During this project, the instructor will need to be actively involved in guiding, pushing, questioning, and assuring the teams. The instructor walks a fine line between (1) pushing the students to conduct cost and revenue research and (2) pushing the students to think creatively at a highly strategic and Socratic level.

Socratic Guided Questions. The role of the instructor in supervising this project is one of the Socratic Guide. The instructor must be careful not to assume the role of the "expert" on the revenues, costs, and cash flows associated with the project. Instead, the instructor needs to push the students with questions, such as:

- How can you interact with and learn from your market?

- $\quad$ How can you learn from other businesses that interact with your market? How do other similar businesses solve this problem? What can you learn from them?

- $\quad$ How can you test whether your revenue projection is reasonable? (For example, if you project $\$ 1,000$ per month for coffee, how many cups per hour are you projecting? Can you serve that many?)

- How could you arrive at a very rough "guesstimate"?

- Does it matter if you have an exact number? What magnitude of "error" would make a difference? How could you test your "guesstimate"?

- What major assumptions do you need to make in order to finish this project? Are they truly critical assumptions (i.e., potential show-stoppers)?

- What do you think you should do in this situation? Why?

The instructor's goal is to push students to think critically and analytically, rather than simply providing them with an expert answer. If the instructor assumes the role of the expert, significant student learning will be circumvented.

Identifying Attendees for the Final Poster Presentation Session. Potential attendees for the session can obviously include other accounting faculty members. However, faculty members from other academic areas (such as Strategy, Marketing, Management, and Entrepreneurship) are a rich source of participants. Alumni, associated community business leaders, and industry experts are also good candidates. For the "Coffee Anyone?" Business Opportunity Statement, the instructor was able to include the Director of Campus Dining Services and the Director of the College Center for Entrepreneurship.

\section{Optional Awards to Enhance Attendee and Student Engagement}

Attendees and students can participate in the evaluation of the student projects by a simple token and "play money" investment system. The suggested awards are for "The Best Visual Display," and "The Best New Business Proposal." The logistics of managing the process are simple and appear below.

- $\quad$ Before the Poster Session, the instructor creates Paper Tokens printed with the words "Best Visual Display" and sheets or packets of $\$ 1,000,000$ in play money. Ten $\$ 100,000$ bills is a useful amount.

\footnotetext{
${ }^{9}$ The Market Build-Up Method of estimating revenues is frequently useful for revenue projection.
} 
- $\quad$ Each team is assigned a number and a color. For example, Team 1 could be assigned the color "green". Two letter-size green paper signs bearing the number " 1 " are created. One sign is posted at the team's Poster Presentation station. The other sign is attached to a large envelope to be used for the Voting Station

- $\quad$ The Voting Station is set up at the front of the room. It is comprised of large color-coded numbered envelopes taped to the front wall or board. Each color-coded envelope matches one of the team display signs.

- $\quad$ Each attendee of the Poster Session receives a "Best Visual Display" token and $\$ 1,000,000$ in play money to invest. After visiting each display, the attendee should discretely visit the Voting Station at the front of the room. At the Voting Station, the attendee casts a token for one team and distributes the investment play money to one or more teams. ${ }^{10}$

- $\quad$ The tokens and the play money are counted after the Poster Session. The winning teams are announced during the last class.

\section{CONCLUSION}

This paper presents a capital budgeting project for teams of senior undergraduate accounting students. This unstructured project requires both the instructor and the students to step outside of their comfort zones of textbooks and homework problems. The students are challenged to develop and apply significant critical thinking skills as they progress through the project. As a result, the students can experience significant technical, professional, and intellectual growth as they proceed through the process of conceiving, budgeting, and evaluating their own new business proposal. The instructor is challenged to step back from the role of expert and to actively participate with the students in the form of guided questions. The project ends with a Poster Session in which the students interact with and receive feedback from other professionals.

\section{AUTHOR INFORMATION}

Katherine J. Silvester, Ph.D. is an Associate Professor of Accounting in the Department of Accounting and Business Law at Siena College in Loudonville, NY. She earned her Ph.D. in Accounting from the University of Maryland in College Park. Her primary teaching and research interests lie in the areas of managerial/cost accounting and accounting pedagogy. She has previously published in journals such as the Journal of Business Case Studies, the Journal of Accounting Case Research, and the Journal of Accounting and Public Policy. E-mail: ksilvester@siena.edu.

\section{REFERENCES}

1. Accounting Education Change Commission (AECC). 1990. "Objectives of Education for Accountants: Position Statement Number One." Issues in Accounting Education (Fall): pp. 307-312.

2. Albrecht, W. Steve and Robert J. Sack. 2000. "Accounting Education: Charting the Course through a Perilous Future.” American Accounting Association Monograph, Accounting Education Series, Volume No. 16.

3. Horngren, C., S. Datar and M. Rajan. 2012. Cost Accounting: A Managerial Emphasis, $14^{\text {th }}$ Edition, New Jersey: Pearson Prentice Hall.

4. Silvester, K., McDermott, C. and R. Veryzer. 2002. “An Integrated Market Immersion Approach to Teaching New Product Development in Technologically-Oriented Teams.” The Journal of Product Innovation Management, 19(1), pp. 18-31.

\footnotetext{
${ }^{10}$ We also allow the students to participate in the voting. Each student is told she can (1) vote/invest in any team, other than her own team or (2) she can opt to not vote/invest. To prevent self-voting, each student receives a token and play money that is the same color as her team. For example, members of Team 1 would each receive a green token and green play money. When counting the money and tokens after the session, any green tokens or green play money that appears in the Team 1 green envelope can be discarded.
} 


\section{APPENDIX A}

\section{Business Opportunity Statement \\ "Coffee Anyone?}

Stanton College is a small, Liberal Arts residential College located outside of Boston, Massachusetts. Its 3,000 students are evenly distributed among its three major schools of Liberal Arts, Science, and Business. The major academic building on campus, Stanton Hall, is over 70 years old and located upon the main academic quad of the school. Approximately, 500 students enter Stanton Hall on a daily basis, 5 days per week, during the standard academic semester. Night, weekend, and summer traffic is relatively light. Although a major renovation of Stanton Hall was completed three years ago, no provision was made for food and beverage services at that time.

Students and professors in Stanton Hall have been complaining about the lack of beverage and snack services available in the building. In general, students must go to the main Campus Dining Hall, off-campus eateries, or bring their own food if they want to eat or snack. Professors have similar concerns, although currently they do have access to a Faculty Lounge on the second floor of Stanton Hall. This Lounge includes some comfortable furniture and access to coffee, tea, a microwave, and a small refrigerator.

Some comments from students in Stanton Hall include:

a. "I just want to be able to grab a quick cup of coffee between classes"

b. " "It would be nice to be able to get a small snack, a pastry, or something...."

c. "I can’t even heat up my own food, if I bring it!"

d. "Not all of us drink coffee, and sometimes I just want something cold to drink...."

e. $\quad$ "I don't have time to go to the Dining Hall, but I'm hungry!"

f. "It gets so hot in Stanton Hall in the summer, and it gets so cold in the winter...."

g. "I get tired of Dining Hall food..... I want something different."

Some comments from the Building Custodial Team include:

a. "I don't want to deal with a lot more mess in Stanton Hall!"

b. "Students already track in a lot of mud, dirt, and snow. Increased traffic would bring in even more mess."

c. "Space is at a real premium at Stanton College. I don't think there is a spare classroom or meeting room anywhere on campus during the day class times."

d. "Stanton Hall is really crowded during class changes. I can't even imagine dealing with lines of students for coffee, etc. How would you deal with congestion in the halls?"

Stanton Hall faculty comments include:

a. "I wish I could get a GOOD cup of coffee. I'm more of a coffee gourmet.... So, I don't like the Faculty Lounge coffee that is provided."

b. "I don't want to have tons of students lounging in the hall outside my office, slurping and spilling drinks, and leaving trash in the halls..."

One faculty member distributed an e-mail earlier this semester, addressing his desire for an up-scale coffee cafe. His edited e-mail appears below for your consideration.

Dear Colleagues,

.... For years, I have been trying to set up a nice welcoming environment for student-faculty interaction. We talk rightly about the importance of this exchange on a social/academic level. I have been trying to set up a nice, classy, espresso bar (barista) on campus that would emulate the Starbuck's welcoming atmosphere. It would have a high quality espresso machine, some soft music, tables, easy chairs, and coffee tables. This project is starting to pick up interest and some momentum. My wife and I have even offered to make a donation to Stanton to make this a reality. Right now, we are looking at classy, centralized places on campus. 
My question is, "Would there be any faculty interest in such an espresso café? Can you envision, as I can, telling students, "I often have an espresso and a sweet around 3; if you see me there, by all means feel free to sit down and chat."

I see this as a great venue to continue an after-class discussion with our students. It would also provide a setting for faculty interchange, as well. I would like some feedback on how feasible this is. When would faculty be most likely to use such a facility? Would you miss your own local coffee pot with a brew like boiled oil at the end of a long day? Please give me some feedback and advice.

Professor J. Jackson

\section{Overview of Your Group Project:}

1. Collect all additional information that you deem appropriate and necessary.

2. Formulate a business response/solution to this Business Opportunity Statement.

3. Analyze and evaluate the financial viability of your proposed solution.

4. Refer to the Team Project Description (Appendix B) for the detailed Project Requirements, Deliverables, and Due Dates. 
APPENDIX B

\author{
Team Project Description \\ Detailed Project Requirements, Deliverables, and Due Dates
}

\title{
General Project Information
}

\section{$\underline{\text { Overview }}$}

Your group must prepare and present a proposal for a new "for profit" privately-owned business. The description of the needs that the new business must fulfill is included in a separate "Business Opportunity Statement." You must describe, budget, and evaluate (in detail) the new business or project that your company is proposing to undertake.

You must project the project's annual after-tax cash flows, after-tax accounting numbers, and the performance measures that are relevant to your capital budgeting decision over an appropriate analytical time period.

You must evaluate whether or not we should fund your project from our limited capital resources. We have up to $\$ 5$ million to invest at this time.

It is important that your analysis be objective, detailed, professional, and accurate. Your final project recommendation must be either: Fund or Do Not Fund. Your grade is dependent upon the depth and quality of your work, as well as upon the objectivity of your final funding recommendation. Your grade is NOT dependent upon a positive funding recommendation.

You must maintain an organized Project Notebook that contains all of your work (background materials, calculations, spreadsheets, resource references, handwritten notes, drawings, surveys, photographs, etc.) Your Project Notebook will be reviewed at the Final Poster Presentation in order to determine the quality, organization, depth, and accuracy of your research and work.

$\underline{\text { Deliverables }}$

\begin{tabular}{|c|l|l|c|}
\hline & \multicolumn{1}{|c|}{ Deliverable } & \multicolumn{1}{|c|}{ Due Date } & \multicolumn{1}{|c|}{$\begin{array}{c}\text { \% of Project } \\
\text { Grade }\end{array}$} \\
\hline 1 & Team Proposed Solution to Business Opportunity Statement & Third Week of Class & $9 \%$ \\
\hline 2 & $\begin{array}{l}\text { Draft of Detailed After-Tax Cash Flow Analysis in Excel, with Conversion } \\
\text { and Reconciliation to After-Tax Net Income. }\end{array}$ & $\begin{array}{l}\text { One Month Before } \\
\text { Final Presentation }\end{array}$ & $40 \%$ \\
\hline 3 & $\begin{array}{l}\text { Final Poster Presentation, with Executive Summary \& Notebook of } \\
\text { Supporting Work }\end{array}$ & Last Week of Class & $50 \%$ \\
\hline 4 & Submitting an Individual Peer Review & Last Day of Class & $1 \%$ \\
\hline
\end{tabular}

\section{$\underline{\text { General Project Guidelines }}$}

- Primary research is more highly valued (and rewarded) than secondary research. In other words, conducting surveys, observing real business operations, and interviewing real people is vastly preferred over internet research.

- When hard data is not available or accessible for your project, you can use common sense estimates. However, be sure to list your assumptions, as well as your actual sources, in your Project Notebook.

- Your overall combined income tax rate is $25 \%$, and your firm's Cost of Capital is $6 \%$.

- Your firm uses the straight line depreciation method over the estimated useful life of the asset for both financial and tax purposes. (This is a simplifying assumption.)

- You may assume that inflation is non-existent. 


\section{Peer Evaluations}

Following your Final Poster Presentation, each group member is required to complete a peer evaluation. These peer evaluations can significantly affect each team member's grade. Theoretically, a team could receive an "A" on its project, while a completely non-contributing team member could receive a Zero, instead of the team "A".

\section{Deliverable 1 \\ Description of Team Proposed Solution}

Prepare a detailed description of your proposed solution to the Business Opportunity Statement.

- $\quad$ Explain how your proposed solution will address the issues raised in the Business Opportunity Statement.

- Include the names and locations of businesses that you intend to visit, observe, and photograph. These businesses must be relevant to your proposed solution.

\section{Deliverable 2 \\ Draft of Detailed After-Tax Cash Flow Analysis}

Prepare a print-out of your Summarized After-Tax Cash Flow Spreadsheet for your instructor to review. The Summarized Spreadsheet must include:

- $\quad$ Relevant Years of Analysis of the Project's Projected Life

- $\quad$ Short Descriptive Title for Each Projected Annual Cash Flow, (e.g., asset purchases, cash sales, business expenses [salaries, utilities, cost of goods sold, etc.], depreciation tax shield, tax effect from accounting gain/loss from asset disposals...)

- $\quad$ Before-Tax Cash Flow Dollars and After-Tax Cash Flow Dollars for each Description

- $\quad$ Reconciliation of Total After-Tax Cash Flows to Total After-Tax Net Income.

Please note that you must also bring print-outs of all of your detailed supporting schedules with you for review. This should include details regarding the cash inflows and cash outflows that you are predicting.

\section{Deliverable 3 Final Poster Presentation}

Attire: Business Formal

The Group Poster Presentations/Displays are scheduled for the last week of classes. All of the presentations will be set up in a room for simultaneous viewing. Visitors will attend the presentations/displays, and their feedback can impact your project grade. Each team must present their project to the visitors as they stop at your Display. You should expect the visitors to have lots of questions and suggestions regarding your Proposal.

During the session, the visitors will assess your work. At the end of the session, each visitor will vote for the team with the "Best Visual Display" and the team with the "Best New Business Proposal." The winners will be announced at the last class session. The visitors' input will factor into each team's Deliverable 3 grade.

The following deliverables are due at the Poster Presentation.

\section{1. $\quad$ Tri-Board Poster}

The team should prepare a Tri-Board Poster presenting your new business proposal. You must specifically address the following issues on your poster.

- Describe your new company. What needs does it address? What is its size? How and where does it operate? 
- What did you learn by observing another company's similar operations? Tell us about your observation experience. Show pictures!

- What Quality Measures will your company track? How will it collect the data? How will you use this feedback to improve operations?

- What are your major projected financial numbers and measures?

- Annual After-Tax Cash Flows, Revenues, Expenses, Net Income, Accounting Rate of Return.

- Project's Net Present Value, Internal Rate of Return, and Payback Period.

- What is your final funding recommendation?

2. $\quad$ Executive Summary of Project and Recommendation (2 pages)

- You must prepare a 2 page, double-spaced, typed Executive Summary of your Proposal, including your Funding Recommendation.

- Copies of the Executive Summary should be available for distribution to visitors as they visit your display.

3. Detailed Cash Flow Analysis in Excel (Place in Project Notebook)

- After-Tax Cash Flow Spreadsheet

- The Annual Income Statements

- The Reconciliation of the After-Tax Cash Flow Spreadsheet to the Annual Income Statements

- Performance Measure Calculations - (the Project's Internal Rate of Return, the Project's Payback Period, the Project's Net Present Value, and the Annual Accounting Rate of Return for each year in the project's life).

4. $\quad$ Organized Project Notebook of Work

- All of your research, analysis, spreadsheets, and analysis should be assembled and organized into a 3ring notebook and submitted on the day of the presentation. Include all of your background information and sources in the notebook, so that we can see the amount and quality of research that you have done.

\section{Deliverable 4 \\ Individual Peer Review}

Following your Final Poster Presentation, each group member is required to complete a confidential peer evaluation. These peer evaluations can significantly affect a team member's grade. Theoretically, a team could receive an "A" on its project, while a completely non-contributing team member could receive a Zero, instead of the team "A". 


\section{APPENDIX C}

\section{Sample Cash Flow Spreadsheet}

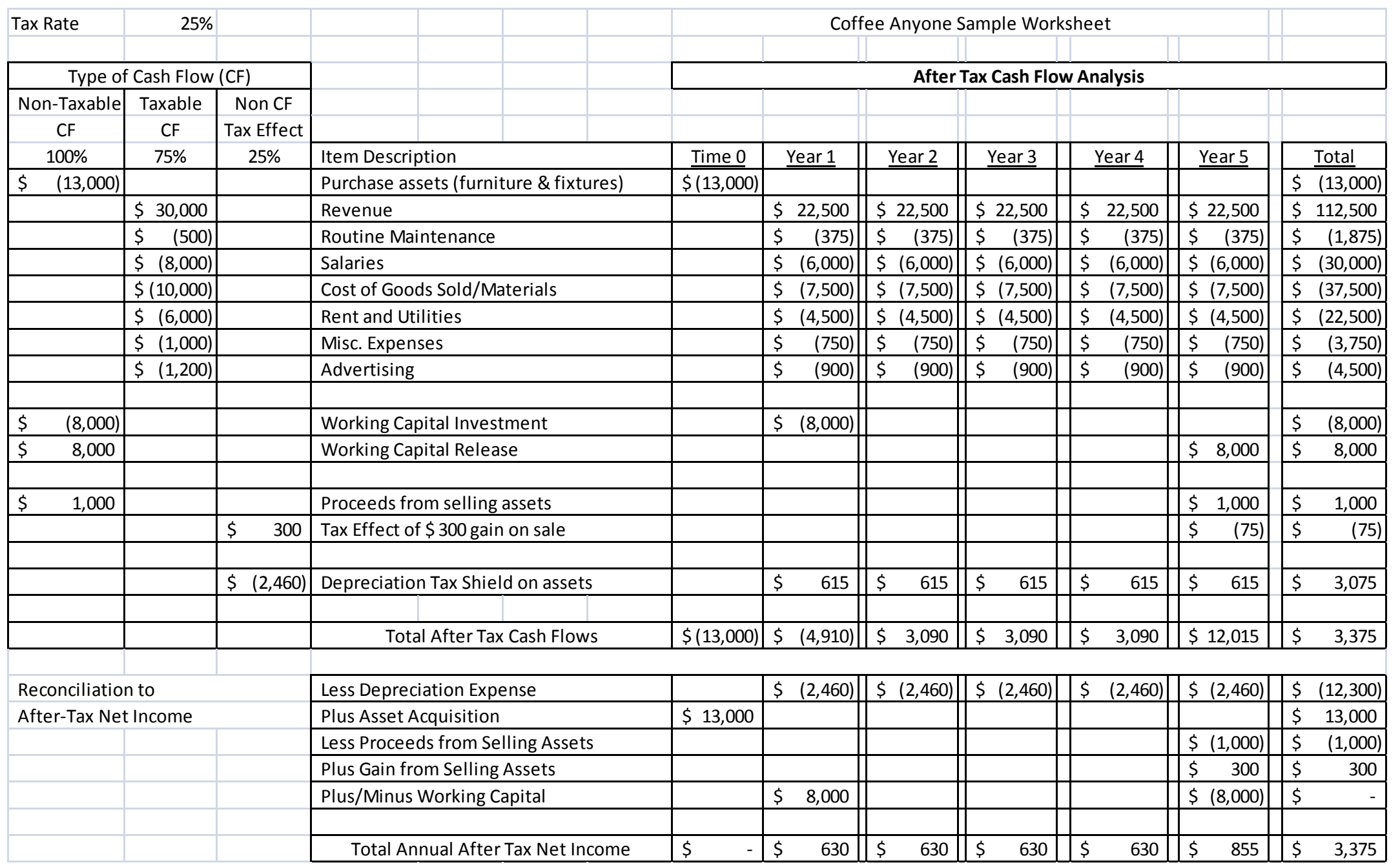




\section{APPENDIX D}

Sample Income Statement

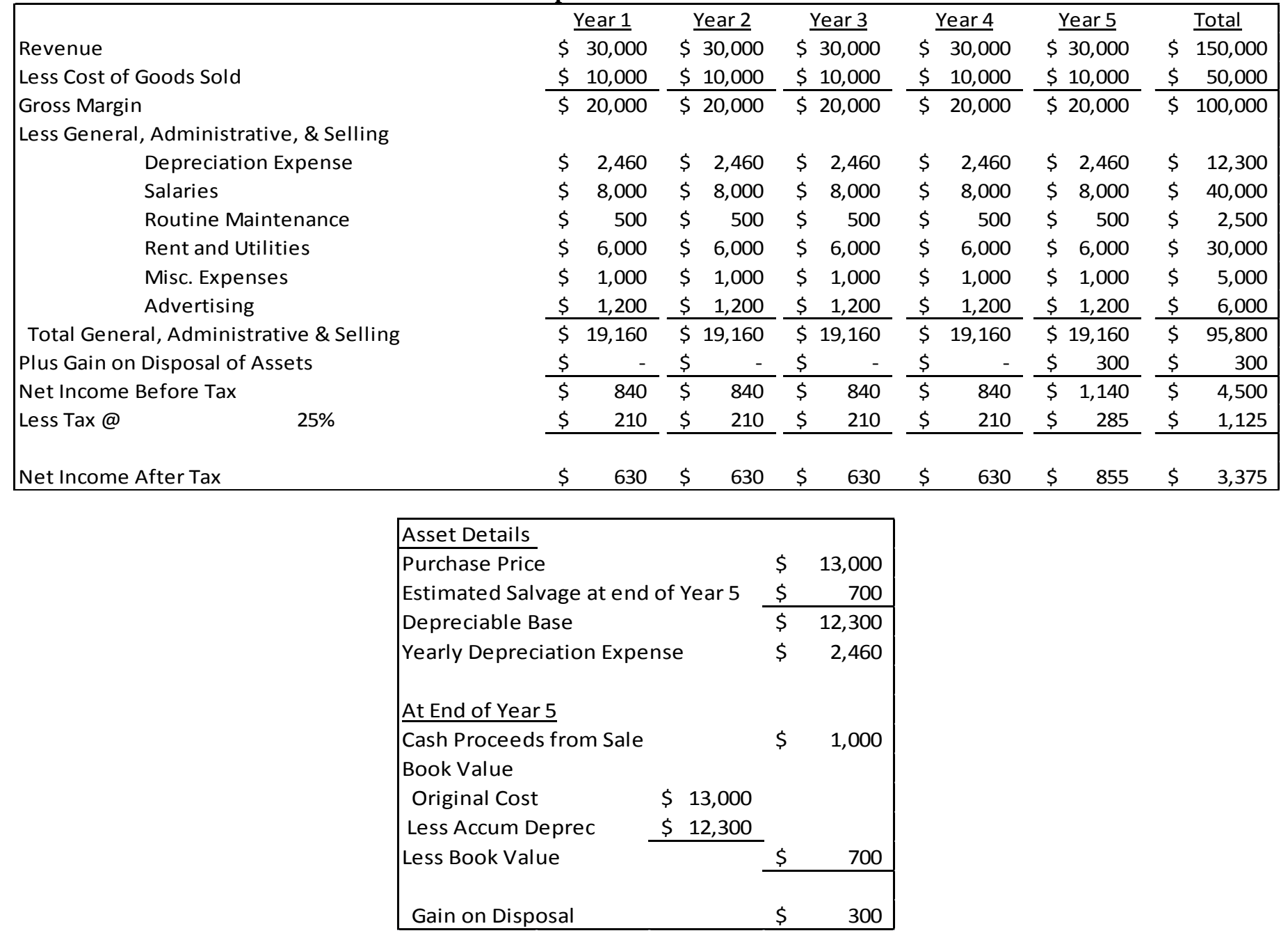




\section{APPENDIX E}

\section{*Confidential Peer Evaluation}

Name:

Date Due: Last Class of Semester

Please list the names of the people on your team, including yourself. Then divide up 100 points among all of the team members, including yourself. For example, on a 4 person team, if everyone contributed equally, each person would receive 25 points.

* "Confidential" means that each individual will only be given access to his/her AVERAGE score from their team members. As an example, assume Mary is on a 4 person team. She is given a 25 by John, a 20 by Joe, and a 21 by Ellen. If she inquires, Mary will be told that her average peer review was a 22.

$\underline{\text { Name of Team Member }}$

$\underline{\text { Points }}$

Total Points

100

Is there any additional information that I should have to fairly evaluate each team member's contribution to your project? If yes, please explain on a separate sheet or on the back of this sheet. 
NOTES 